\title{
Erratum to: A multicenter case-control study of diagnostic tests for urinary tract infection in the presence of urolithiasis
}

\author{
S. Yilmaz $\cdot$ M. Pekdemir $\cdot$ N. M. Aksu • \\ N. Koyuncu $\cdot$ O. Cinar $\cdot$ E. Akpinar
}

Published online: 1 May 2012

(C) Springer-Verlag 2012

Erratum to: Urol Res (2012) 40:61-65

DOI 10.1007/s00240-011-0402-x

Unfortunately, one author name was inadvertently not included in the author group/affiliation of the original publication. The complete authors group should read as:

S. Yilmaz · M. Pekdemir · N. M. Aksu · N. Koyuncu •

O. Cinar · E. Akpinar

The online version of the original article can be found under doi:10.1007/s00240-011-0402-x.

S. Yilmaz $(\bowtie) \cdot$ M. Pekdemir

Department of Emergency Medicine, School of Medicine,

Kocaeli University, 41380 Kocaeli, Turkey

e-mail: serkanyilmaz@kocaeli.edu.tr

M. Pekdemir

e-mail: mpekdemir@kocaeli.edu.tr

N. M. Aksu

Department of Emergency Medicine, School of Medicine,

Hacettepe University, Ankara, Turkey

e-mail: nametaksu@yahoo.com

N. Koyuncu

Department of Emergency Medicine, Bayındır Medical Center,

Ankara, Turkey

e-mail: koyuncunazmiye@yahoo.com

O. Cinar

Department of Emergency Medicine, Gulhane Military Medical,

Academy, Ankara, Turkey

e-mail: orhancinar@yahoo.com

E. Akpinar

Department of Radiodiagnostic, School of Medicine,

Hacettepe University, Ankara, Turkey

e-mail: erhan.akpinar@gmail.com 